\title{
AN ANALYSIS ON THE DIFFICULTIES LEVEL OF THREE ONLINE WRITTEN TEXTS
}

\author{
WANDA GIOVANI \\ Pamane Talino College of Education \\ Jalan Afandirani, Ngabang, Landak, Kalimantan Barat \\ wandotwandot@gmail.com
}

First Received: 29-02-2020; Accepted: 05-03-2020

\begin{abstract}
This research aims to elaborate the difficulty levels of three different texts that bring the same topic. This research is a discourse analysis which was done by analyzing the lexical density, nominalization, and the finiteness of the texts. The three texts that have been analyzed were taken online from Wikipedia and two personal blogs for English research. The results show that the first text can be taken as the most complex text for high level readers, the second text for the intermediate level readers, and the third text for the elementary or low level readers. In terms of lexical density, the first text gains very high percentage which is up to $60 \%$, this shows that the text is the most informative of all. Whereas, the second text and the third text's lexical density are both $50 \%$, which indicates that there are lack of contents in them. Regarding to nominalization, the first text is still on the highest level with 12 nominalizations, the second text is on the intermediate level with 10 nominalizations, and the third text is on the lowest level, without any nominalization. The last is from the finiteness side. The first text has the lowest number of finiteness; the second text has the second highest number of finites, whereas the third text has the highest number of finites of all. The results of this research can be useful for online readers to decide what kind of reading materials which are suitable for their English levels.
\end{abstract}

Keywords: Online Texts, Lexical Density, Nominalizations, Finiteness.

\section{INTRODUCTION}

There are many ways can be done in researching a social problem, and discourse analysis is one method that can be done. Kridalaksana in Yoce (2009) discusses that discourse is the most complete unit of language in the highest grammatical hierarchy and is the highest or largest grammatical unit. Discourse is a linguistic unit that is larger than a sentence or clause. In this research, the kind of discourse that has become the object of the research is three written online texts, which are; Domestic Dog, Dog, and My Dog.

In conducting a discourse analysis, there are many aspects can be analyzed. One of them is the lexical density. Johansson (2008) states that lexical density is the term which is most often used for describing the proportion of content words (nouns, verbs, adjectives, and 
adverbs) to the total number of words. To know the lexical density of a text is important, because the lexical density determines the quality of the text that is read. The higher the level of lexical density in the text indicates the higher the content of meaning is contained in the text. The high and the low levels of lexical density can be determined by calculating how many lexical items are contained in the text. The lexical items are the types of words that need to be identified, such as: verbs, adverbs, adjectives, and nouns. In this research, the rule which is used to measure the lexical density of the texts is:

Lexical density $=\underline{\text { The Number of Lexical Items x } 100}$

The Total Words

Another aspect which is one of the focuses of this research is nominalization. Nominalization is the use of verbs or adjectives as nouns with or without morphological changes. In English, it can be in form of verbs which is used directly as nouns, or it requires some form of morphological transformation. In this research, the nominalization is represented as abstract nouns, gerunds or participles. Abstract nouns are derived from verbs and adjectives that turn into nouns which are commonly added with the ending -ment, -tion, al, -age, -ity. Gerunds are the transformation of verb into a noun such as sing into singing.

The last focus of this research is finiteness. Finiteness is a number of finites used in the text. Finites carry tense (present/past), agreement (singular/plural), polarity (positive/negative), and modality (can, may, must, etc.). Those finites determine the speech functions used in the text such as declarative, interrogative, or imperative. The high number of finites indicates the high number of sentences contained in a text, because every sentence must have a finite. It is important to take finites into account in deciding the difficulty of a text. A text that contains a high number of finites will be easier to be understood, although the form of the text may be longer than others that have lower number of finites.

\section{METHOD}

This research employs a mix-method which includes both calculation and description. The data are online texts which were taken from Wikipedia and two personal blogs for English research. For calculating the lexical density, this study employs the methods proposed by Castello (2008) which refers to the former method of calculation by Ure (1971) and Halliday (1985). The lexical density represented in the following formula: 
Lexical density $=\underline{\text { The Number of Lexical Items x } 100}$

The Total Words

Whereas for calculating the nominalization, the writer uses table of specification which classify each findings into four types of nominalization, such as; nouns and verbs spelled a like, gerunds, verbs to nouns, and adjectives to nouns. The calculation of finiteness also uses table of specification which classifies the findings into four types of finiteness namely; tenses, modality, negative polarity, and speech functions.

\section{FINDINGS AND DISCUSSION}

\section{1. $1^{\text {st }}$ Text}

\section{Domestic Dog}

The domestic dog (Canis lupus familiaris or Canis familiaris) is a domesticated canid which has been selectively bred over millennia for various behaviours, sensory capabilities, and physical attributes.

Although initially thought to have originated as an artificial variant of an extant canid species (variously supposed as being the dhole, golden jackal, or gray wolf) extensive genetic studies undertaken during the 2010s indicate that dogs diverged from an extinct wolf-like canid in Eurasia 40,000 years ago. Being the oldest domesticated animal, their long association with people has allowed dogs to be uniquely attuned to human behavior, as well as thrive on a starch-rich diet which would be inadequate for other canid species.

Dogs perform many roles for people, such as hunting, herding, pulling loads, protection, assisting police and military, companionship and, more recently, aiding handicapped individuals. This impact on human society has given them the sobriquet, "man's best friend".

Source: https://en.wikipedia.org/wiki/Dog

Table 1 Lexical Density

\begin{tabular}{|c|c|c|}
\hline No & Type of Lexical Items & Total \\
\hline 1 & Verb & 13 \\
\hline 2 & Adverb & 13 \\
\hline 3 & Adjective & 20 \\
\hline 4 & Noun & 46 \\
\hline & Total & 92 \\
\hline
\end{tabular}

Total words in the text $=148$ 


$$
\begin{gathered}
\text { Lexical density }=\frac{92}{148} \times 100 \% \\
\text { Result }=62 \%
\end{gathered}
$$

The dominant type of lexical density is noun which occurs 46 times of 148 words in the text. The second most occurred lexical density is adjectives which is 20 words of 148 . Then there are also the occurrences of verb and adverb which equally appeared 13 times. The total number of lexical density of the text is very high which is $62 \%$ (92 words) of 148 words. This shows that the text above is classified into a high level text in terms of its complexity and content of information. That is why it is suitable to be added in the Wikipedia which is known as one of the internet's largest and most popular general reference work in the world.

\begin{tabular}{|c|c|c|c|c|c|}
\hline & & $\begin{array}{l}\text { Nouns and verbs } \\
\text { spelled a like }\end{array}$ & Gerunds & Verbs to nouns & $\begin{array}{l}\text { Adjectives to } \\
\text { nouns }\end{array}$ \\
\hline 1. & Behaviours & & & $\checkmark$ & \\
\hline 2. & Variant & & & $\checkmark$ & \\
\hline 3. & Species & & & $\checkmark$ & \\
\hline 4. & Association & & & $\checkmark$ & \\
\hline 5. & Hunting & & $\checkmark$ & & \\
\hline 6. & Herding & & $\checkmark$ & & \\
\hline 7. & Pulling loads & & $\checkmark$ & & \\
\hline 8. & Protection & & & $\checkmark$ & \\
\hline 9. & Assisting police & & $\checkmark$ & & \\
\hline 10. & Military & & & $\checkmark$ & \\
\hline 11. & Companionship & & & $\checkmark$ & \\
\hline 12. & $\begin{array}{l}\text { Aiding handicapped } \\
\text { individuals }\end{array}$ & & $\checkmark$ & & \\
\hline
\end{tabular}

Table 2 Nominalization

The table above shows the result of the number of nominalization found in the text. It can be seen that there are 12 words which is included to nominalization there. The most frequent nominalization appears in the text is verbs to nouns which appears seven times. They are behaviours which is derived from behave, variant which is derived from vary, species which is derived from specify, association which is derived from associate, protection which is derived from protect, military which is derived from militate, and companionship which is derived from company. Meanwhile, the other type of nominalization appears is gerund, such 
as hunting, herding, pulling loads, assisting police, and aiding handicapped individuals which are derived from words hunt, herd, pull, assist, and aid. These nominalizations contribute to the lexical density as one of the process to create more nouns in order to carry more contents of the text and to avoid repeating verbs. It also indicates that the text is objective and more formal.

Table 3 Finiteness

\begin{tabular}{|c|c|c|c|c|c|c|c|}
\hline \multirow[t]{3}{*}{ Finites } & \multicolumn{7}{|c|}{ Categorizations } \\
\hline & Ten & & Modality & Negative & & Speech Function & \\
\hline & Present & Past & & polarity & Declarative & Interrogative & Imperative \\
\hline Is & $\checkmark$ & & & & $\checkmark$ & & \\
\hline Has been & $\checkmark$ & & & & $\checkmark$ & & \\
\hline Thought & $\checkmark$ & $\mathrm{v}$ & & & $\checkmark$ & & \\
\hline Indicate & & & & & $\checkmark$ & & \\
\hline $\begin{array}{l}\text { Has } \\
\text { allowed }\end{array}$ & $\checkmark$ & & $\checkmark$ & & $\checkmark$ & & \\
\hline Would & $\checkmark$ & & & & $\checkmark$ & & \\
\hline Perform & $\checkmark$ & & & & $\checkmark$ & & \\
\hline Has given & $\checkmark$ & & & & $\checkmark$ & & \\
\hline
\end{tabular}

The text above shows the finiteness found in the text. Finiteness is a number of finite used in the text. Finite carries tense (present/past), agreement (singular/plural), polarity (positive/negative), and modality (can, would, may, must, etc.). Those finites specify the speech functions used in the text such as declarative, interrogative, or imperative. There are eight finites appear in the text, they are; is, has been, indicates, has allowed, perform, and has given which are included in present form. And the other finites are; thought and would which are included in past form. Both kinds of finites indicate declarative function. There is only one modality found, which is the word would that indicates probability. And there is no negative polarity in the text.

\section{2. $2^{\text {nd }}$ Text}

\section{Dog}

Dogs are one of the most preferred pet in the world. Their height ranged from 12.7 to $86.4 \mathrm{~cm}$. They have four legs where the front leg has five fingers, while the hind leg consists of four fingers. In each finger, they have claws like cats. 
They have ears that can be long and short. Their ears are upright or hanging, and even some of them, ears cut off for reason of appearance.

They have many different hair types. Their hair may be hard, clay, wavy, curly, or long and smooth. Their hair thickness is usually adapted to climatic conditions. The colder the climate, the thicker their hair. The hair is composed of two layers, outer and inner. The outer layer is a coarse hair which protects them from dirt, ice, and snow. Meanwhile, the inner layer is a soft hair and used to prevent loss of body heat.

They are animals that have a strong sense. Hearing and smelling become the best senses among others. A dog is able to listen to the sound very well, much better than the human. Then, they are also able to find a specific scent which is so far from them.

Source: http://www.belajarbahasainggrisku.com/2015/08/contoh-report-text-about-dog-dan$\underline{\text { artinya.html }}$

Table 4 Lexical Density

\begin{tabular}{llc}
\hline No & \multicolumn{1}{c}{ Type of Lexical Items } & Total \\
\hline 1 & Verb & 16 \\
2 & Adverb & 9 \\
3 & Adjective & 25 \\
4 & Noun & 49 \\
Total & \\
\hline
\end{tabular}

$$
\begin{gathered}
\text { Total words in the text }=198 \\
\begin{array}{c}
\text { Lexical density }=\frac{99}{198} \times 100 \% \\
\text { Result }=50 \%
\end{array}
\end{gathered}
$$

The lexical density in the second text which is $50 \%$ of 198 words is lower compared to the first text that reaches $62 \%$ of 148 words. The most frequent kind of lexical density is noun which appears 49 times. It contributes almost the half of all lexical density found in the text. The second dominant kind of lexical density is adjective that gives contribution almost $25 \%$. Whereas the other lexical densities like verb and adverb only occur severally 16 times and 9 times and make contribution for $25 \%$. The lower number of lexical density than the previous text indicates that this text is less complex. Yet, it does not mean that the text has less information. The few number of lexical density here is potentially caused by the writer's intention to make the text become more comprehensible for the common people. That is why, the second text is classified into intermediate level of English text. 
Table 5 Nominalization

\begin{tabular}{|c|c|c|c|c|c|}
\hline & & $\begin{array}{l}\text { Nouns and verbs } \\
\text { spelled a like }\end{array}$ & Gerunds & Verbs to nouns & $\begin{array}{l}\text { Adjectives to } \\
\text { nouns }\end{array}$ \\
\hline 1. & Height & & & & $\checkmark$ \\
\hline 2. & Appearance & & & $\checkmark$ & \\
\hline 3. & Thickness & & & & $\checkmark$ \\
\hline 4. & Outer & & & & $\checkmark$ \\
\hline 5. & Inner & & & & $\checkmark$ \\
\hline 6. & Loss & & & $\checkmark$ & \\
\hline 7. & Heat & & & & $\checkmark$ \\
\hline 8. & Hearing & & $\checkmark$ & & \\
\hline 9. & Smelling & & $\checkmark$ & & \\
\hline 10. & Scent & & & $\checkmark$ & \\
\hline
\end{tabular}

There are 10 words which belong to nominalization in the second text. Two gerunds are hearing and smelling, three verbs to nouns like; appearance which is derived from verb appear, loss from verb lose, and scent from verb scent, and also five adjectives to nouns such as; height from adjective high, thickness from adjective thick, heat from adjective hot, and inner and outer which in the sentence context belong to nouns, still derived from the adjectives inner and outer. The nominalization in the second text is not as much as found in the first text, yet it is not very lower either that only differentiated by two margins. It means that this text is quite concise and relevant for intermediate reading level.

Table 6 Finiteness

\begin{tabular}{|c|c|c|c|c|c|c|c|}
\hline \multirow[t]{3}{*}{ Finites } & \multicolumn{7}{|c|}{ Categorizations } \\
\hline & \multicolumn{2}{|c|}{ Tenses } & \multirow[t]{2}{*}{ Modality } & \multirow{2}{*}{$\begin{array}{c}\text { Negative } \\
\text { polarity }\end{array}$} & \multirow[b]{2}{*}{ Declarative } & \multirow{2}{*}{$\begin{array}{l}\text { Speech Function } \\
\text { Interrogative }\end{array}$} & \multirow[b]{2}{*}{ Imperative } \\
\hline & Present & Past & & & & & \\
\hline Are & $\checkmark$ & . & & & $\checkmark$ & & \\
\hline Ranged & & & & & $\checkmark$ & & \\
\hline Have & $\checkmark$ & . & & & $\checkmark$ & & \\
\hline Has & $\checkmark$ & . & & & $\checkmark$ & & \\
\hline Consists & $\checkmark$ & & & & $\checkmark$ & & \\
\hline Have & $\checkmark$ & & & & $\checkmark$ & & \\
\hline Have & $\checkmark$ & & & & $\checkmark$ & & \\
\hline Are & $\checkmark$ & . & & & $\checkmark$ & & \\
\hline Have & $\checkmark$ & & & & $\checkmark$ & & \\
\hline May & $\checkmark$ & & $\checkmark$ & & $\checkmark$ & & \\
\hline Is & $\checkmark$ & & & & $\checkmark$ & & \\
\hline Is & $\checkmark$ & & & & $\checkmark$ & & \\
\hline Is & $\checkmark$ & & & & $\checkmark$ & & \\
\hline Is & $\checkmark$ & . & & & $\checkmark$ & & \\
\hline Protects & $\checkmark$ & & & & $\checkmark$ & & \\
\hline Is & $\checkmark$ & & & & $\checkmark$ & & \\
\hline
\end{tabular}




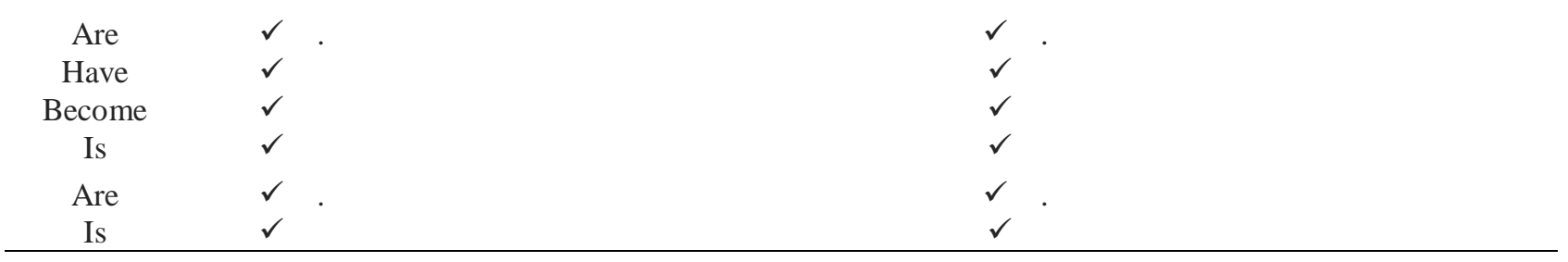

The number of finites occur in the second text is higher than the first text, it is 22 times. The high number of finites occurrence here caused by the high number of sentences found in the text. Even so, the kinds of finite occur in the text is not as much as the frequency number, because there are some finites like is, are and have that repeated several times (is for 7 times, are for 4 times, and have for 5 times). The repetition of finites here is the indication of the lack of lexical density in the text. The other finites found are; ranged, has, consists, may, protects and become. These finites are all classified into declarative function; it is according to the genre of the text which is a report text. There is only one finite that belongs to modality, that is may, and there is no finite included to negative polarity. All finites are in present form, except ranged that is in past form.

\section{3. $3^{\text {rd }}$ Text}

\section{My Dog}

I have a beautiful dog. He is my baby, and he is sweet like a vanilla ice cream. He is really cute, and he is like a little baby, because he is very lovely. When he was a baby he was like a little cat, because his ears are like cat's ears and because he doesn't likes take a bath.

He is not big, but not small. He is black and white like a cartoon cow. His eyes are blue like two pieces of sky, and they are bright like clean glasses. His name is Lobo, because he is like a real wolf, and because he wails like a wolf too.

$\mathrm{He}$ is a Siberian Husky, and this is the reason why he is like a wolf. He makes me very happy, and I love him with all my heart, and I think that he loves me too, and I am going to take care of him, and love him all my life.

Source: http://jhanuarpratama.blogspot.co.id/2014/11/contoh-descriptive-text-tentanganjing.html 
Table 7 Lexical Density

\begin{tabular}{lll}
\hline No & Type of Lexical Items & Total \\
\hline 1 & Verb & 11 \\
2 & Adverb & 6 \\
3 & Adjective & 21 \\
4 & Noun & 45 \\
Total & 83 \\
\hline
\end{tabular}

Total words in the text $=163$

$$
\begin{aligned}
\text { Lexical density } & =\frac{83}{163} \times 100 \% \\
\text { Result } & =50 \%
\end{aligned}
$$

The lexical density of the third text is the same with the second text; it is $50 \%$ of 163 words. Just like the two previous texts, nouns contribute most with 45 words, followed by adjectives with $25 \%$ contribution or 21 words from 83 lexical items, and verb with 11 words, and the last is adverb which only contributes 6 words. This third text is a very simple text that is intended for the elementary readers, that is why the lexical density is no more than $50 \%$. The low frequency of verb and adverb indicates the less of objective information in the text. It is according to the kind of the text which is a descriptive text that can include the writer's opinions about the topic which is not based on scientific facts, yet tends to be more based on her/his perception.

Table 8 Nominalization

\begin{tabular}{clccc}
\hline & $\begin{array}{l}\text { Nouns and verbs } \\
\text { spelled a like }\end{array}$ & Gerunds & Verbs to nouns & $\begin{array}{l}\text { Adjectives to } \\
\text { nouns }\end{array}$ \\
\hline- & - & - & - & - \\
\hline
\end{tabular}

There is no nominalization found in the text. This shows how simple the text is. There might be a lot of nouns found, yet there is no nominalization found. The writer made the text as obvious as possible, means that there is no compressed sentence that can result into confusion in finding the information for the low level readers.

Table 9 Finiteness

\begin{tabular}{lcccccc}
\hline Finites & \multicolumn{2}{c}{ Tenses } & Modality & \multicolumn{2}{c}{ Categorizations } & Negative \\
& polarity & Declarative & $\begin{array}{c}\text { Speech Function } \\
\text { Interrogative }\end{array}$ & Imperative \\
\hline Have & Present & Past & & & $\checkmark$ & \\
Is & $\checkmark$ & & $\checkmark$ & \\
Is & $\checkmark$ & & $\checkmark$ & \\
Is & $\checkmark$ & & $\checkmark$ & \\
Is & $\checkmark$ & & $\checkmark$ & \\
Is & $\checkmark$ & & $\checkmark$ & \\
\hline
\end{tabular}




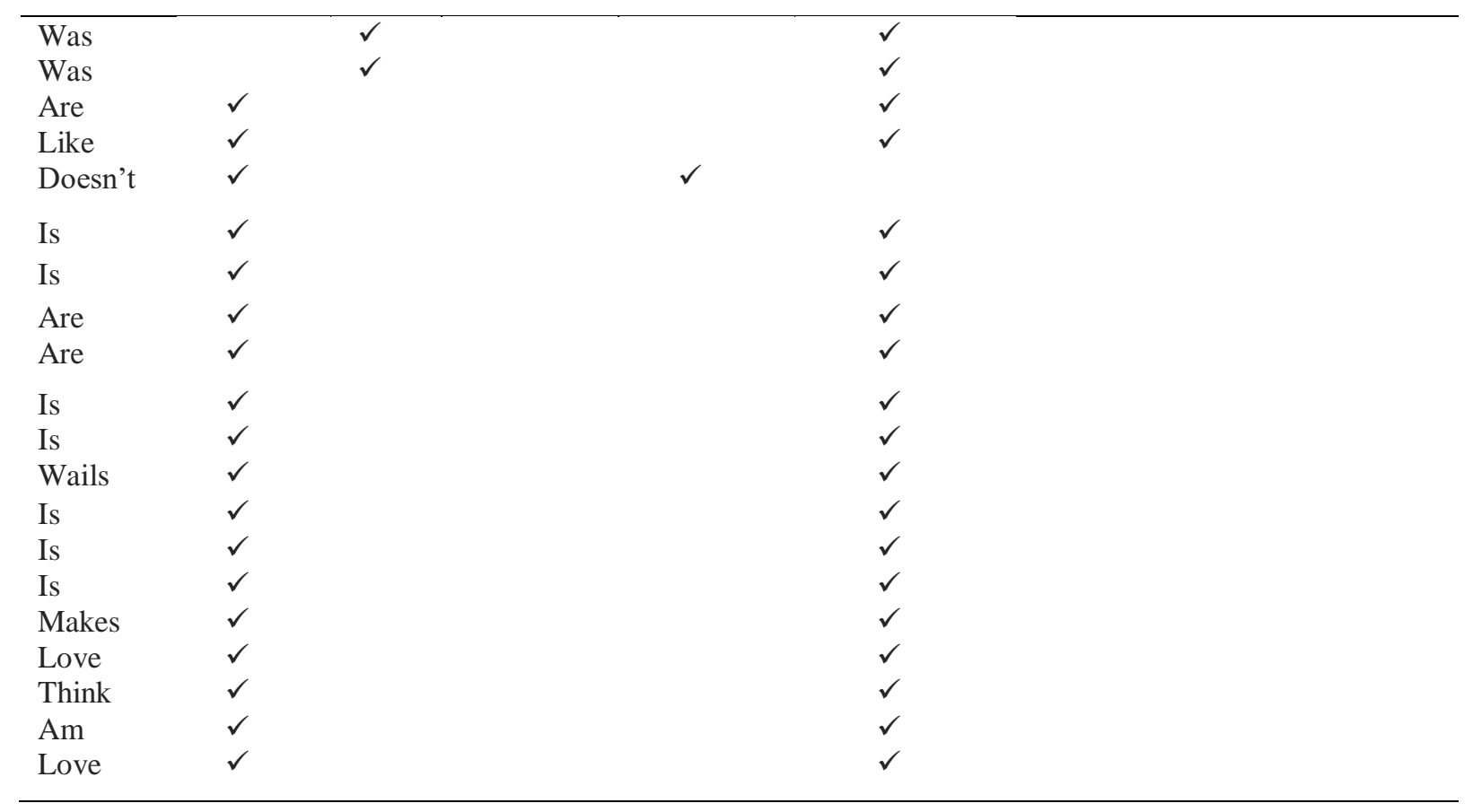

In contrast with its number of lexical items and nominalization, the number of finites found in the third text is much higher. It is even higher than the two previous texts. The finites frequency of this text is 25 from 163 words. They are all included in declarative function, and mostly into present tense, except was and were that belong to past tense. There is no modality, and there is only one negative polarity. The high number of finites here does not represent the complexity of the text; in fact, it shows how simple the text is. There is no nominalization results on the high number of sentence created. The higher the number of sentence, the more finite occurs. This is done in order to reveal the information as obvious as possible to reach the low level of reader's comprehension. There is also repetition of finites, like is for 12 times, are for 3 times, and was for 2 times which also represent the low of lexical density and zero nominalizations.

\section{CONCLUSION}

The level of difficulties from the three texts is supported by the number of lexical density, nominalization, and finiteness in each text. In which the first text can be taken as the most complex text for high level readers, the second text for the intermediate level readers, and the third text for the elementary or low level readers. In terms of lexical density, the first text 
gains very high percentage which is up to $60 \%$, this shows that the text is the most informative of all. Whereas, the second text and the third text's lexical density are both $50 \%$, which indicates that there are lack of contents in them.

Regarding to nominalization, the first text is still on the highest level with 12 nominalizations, the second text is on the intermediate level with 10 nominalizations, and the third text is on the lowest level, without any nominalization. This means that the first text is the simplest in terms of quantity of words, yet the richest in terms of quality of words.

The last is from the finiteness side. The first text has the lowest number of finiteness; the second text has the second highest number of finites, whereas the third text has the highest number of finites of all. This is the result of the highest number of lexical density and nominalization of the first text that decreases the frequency of sentences in it. The high number of finites indicates the low of lexical density and nominalizations.

\section{REFERENCES}

Darma, Yoce Aliah. (2009). Analisis Wacana Kritis. Bandung: CV Yrama Widya

Kridalaksana, Harimurti. (2009). Kamus Linguistik. Jakarta: PT Gramedia.

Johansson, Victoria. (2008). Lexical Diversity and Lexical Density in Speech and Writing: A Developmental Perspective. Working Press, 53: 61-79

Ure, J. (1971). Lexical density and registerdifferentiation. In G. Perren and J.L.M.Trim (eds), Applications of Linguistics, London: Cambridge University Press.443-452.

Castello, E. (2008). Text Complexity and Reading Comprehension Tests Reading Notes. http://adrien.barbaresi.eu/blog/e-castello-text-complexity-and-reading-comprehension-testsreading-notes.html 